LBL-PUB -5344

DE92 016998

\title{
LAWRENCE BERKELEY LABORATORY SELF-ASSESSMENT PROGRAM IMPLEMENTATION PLAN
}

\author{
Office of Assessment and Assurance \\ Lawrence Berkeley Laboratory \\ University of California \\ Berkeley, California
}

June 1992

Prepared for the U.S. Department of Energy under Contract No. DE-AC03-76SF00098 


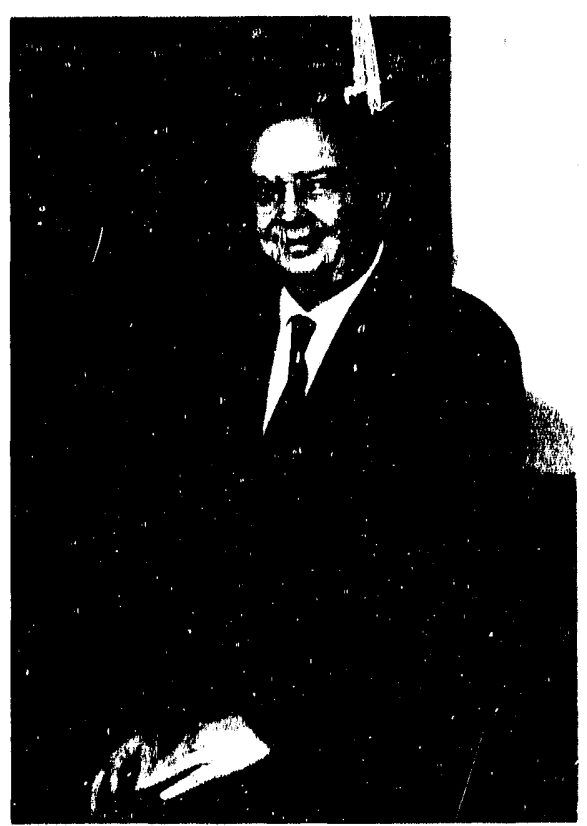

Charles V. Shank, Director

\section{DIRECTOR'S STATEMENT}

All employees of the Lawrence Berkeley Laboratory are faced with a major challenge - to promote a culture here that will lead to continuing improvement in our operations.

The Self-Assessment Program is an essential ingredient in meeting this challenge. It makes self-assessment a part of dayto-day operations at LBL, and allows management and staff to target those areas that need improvement.

As we work together, self-assessment should enable us to correct problems that have resisted past corrective efforts and deal with Lab-wide problems in a systematic and uniform, rather than piecemeal, manner. Working together, we will set measurable performance goals and objectives, analyze our progress, and then communicate our results.

Ongoing self-assessment will inevitably improve our old ways of doing business, but there is also another benefit. Lawrence Berkeley Laboratory is the oldest of the national laboratories, and many of our facilities are dated. Facility shortcomings often play a direct role in creating environmental, health, and safety deficiencies. Data and findings from the Self-Assessment Program will identify facility deficiencies and, in so doing, strengthen the case with the Department of Energy for upgrading our facilities.

There is much to be gained from your participation in this important process. I ask each member of the Lawrence Berkeley Laboratory to assist in this endeavor.

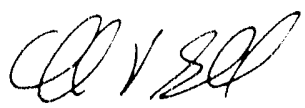

Charles V. Shank 


\section{CONTENTS}

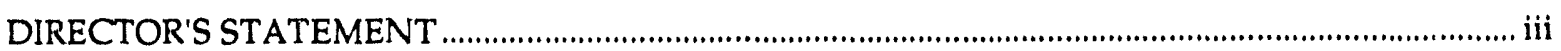

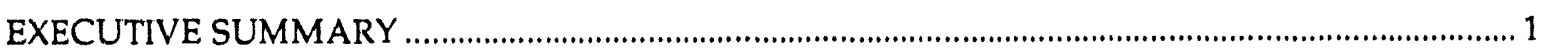

INTRODUCTION …

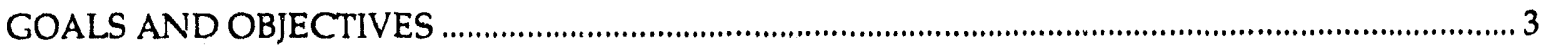

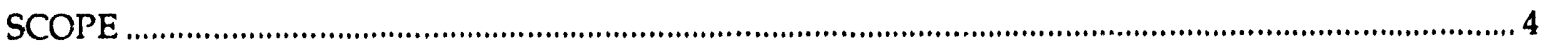

IMPLEMENTATION AUTHORITY AND RESPONSIBILITIES FOR SELF-ASSESSMENT .............. 4

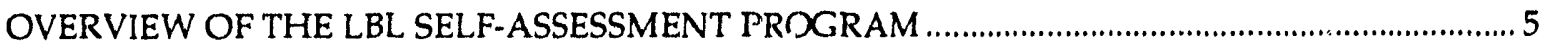

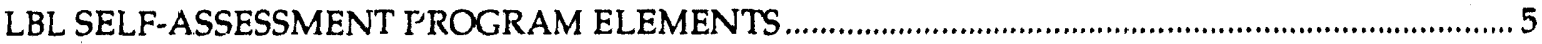

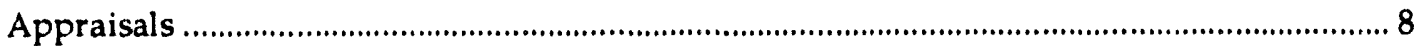

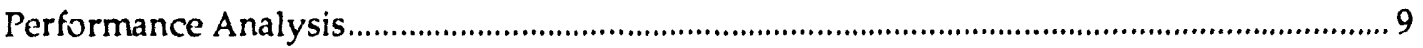

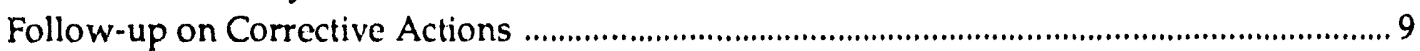

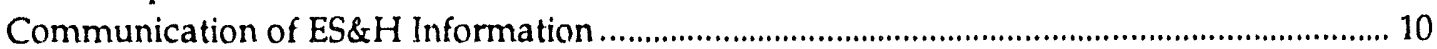

Training of Appraisal and Performance Analysis Teams ..................................................... 10

PROCEDURES FOR DIVISIONS AND OFFICES TO IMPLEMENT SELF-ASSESSMENT .................. 10

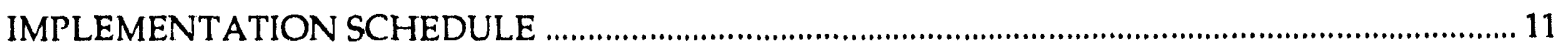

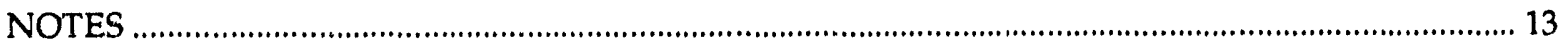

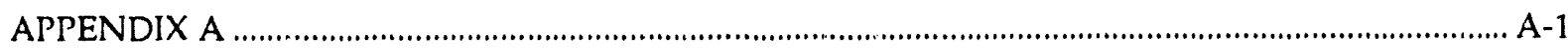

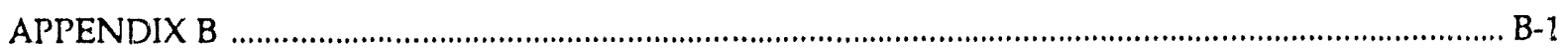




\section{FIGURES}

\section{TABLES}

1 Example of Performance Objectives and

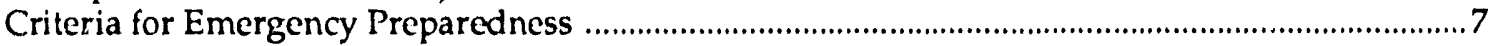

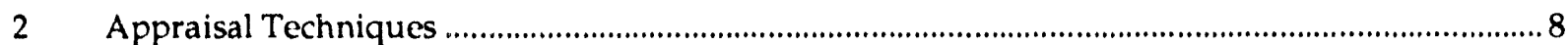

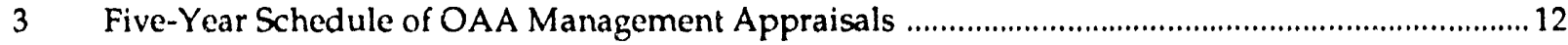

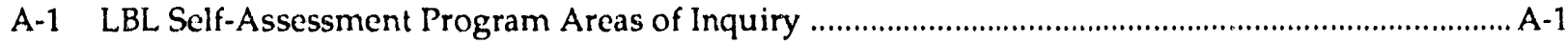




\section{EXECUTIVE SUMMARY}

The Lawrence Berkeley Laboratory (LBL) has established a Self-Assessment Program that provides a formal process for assuring quality and regulatory compliance in all facets of Laboratory operations. This continuous process of information-gathering determines whether procedures designed to achieve quality performance are being followed adequately and, if they aren't, what corrective actions are appropriate.

The LBL Self-Assessment Program formalizes and supplements existing Laboratory self-asses: ment procedures. It ensures accountability, allows trend analyses, and improves communication of environmental, safety and health (ES\&H) information. Although the initial focus and catalyst for implementing a formal self-assessment program is to achieve ES\&H objectives, the program described in this document may be used to evaluate other, non-ES\&H objectives as they are identified by Laboratory management or DOE requirements.

In the LBL program, each Division and Office is responsible for implementing its individual program, with oversight provided by the Environment, Health and Safety (EH\&S) Division and the Office of Assessment and Assurance (OAA).

One element of the LBL Self-Assessment Program is a three-tier appraisal process through which each Division and Office is evaluated by:

- The Division's/Office's Appraisal Team,

- An Environment, Health and Safety Division Functional Team, and

- An OAA Management Appraisal Team.

Appraisals are conducted at varying intervals, deperiding on the type of appraisal and the degree of hazard or risk associated with the operation. Divisions/Offices conduct self-appraisals annually to evaluate their performance in following ES\&H, quality assurance, conduct of operations, and other procedures. The Environment, Health and Safety Division conducts triennial functional appraisals of Divisions'/Offices' compliance with ES\&H procedures. The OAA conducts triennial management appraisals of selective line management activities to evaluate the effectiveness of Divisions/Offices in ensuring that ES\&H, quality assurance, conduct of operations, and other program goals are being met.

Other elements of the LBL Self-Assessment Program are:

- Development by OAA of Performance Objectives and Criteria

- Training of Appraisal Teams

- Analysis of Root Causes and Trends

- Follow-up of Corrective Actions

The Notebooks system, developed by LBL to satisfy quality assurance, conduct of operations, and other DOE requirements, is a primary source of documentation for self-assessment activities. 


\section{INTRODUCTION}

The Lawrence Berkeley Laboratory (LBL) Self-Assessment Program provides a formal process for assuring quality and regulatory compliance in all facets of Laboratory operations. The program, which integrates the ongoing self-assessment activities of the individual Divisions and Offices in a comprehensive, top-to-bottom process, provides assistance to the U.S. Department of Energy (DOE), the University of California, and Laboratory management in their appraisals of Laboratory performance.

This document describes the program goals, scope, responsibilities, elements, and implementation schedule. This document is also the implementation plan for the institutional level self-assessment program. Each Division is also required to develop a self-assessment program that contains the elements described in this document.

\section{BACKGROUND}

In July 1990, concern over environmental, safety and health (ES\&H) performance at all DOE facilities prompted Secretary of Energy Watkins to issue guidance on self-assessment. In February 1991, the Tiger Team Assessment of the Laboratory found that a more formal and institutionalized self-assessment program was needed to track the ability of ES\&H programs, individually and collectively, to meet established performance objectives. While ES\&H programs were implemented at the Laboratory in response to DOE Orders and perceived needs, their implementation was not adequately tracked, formalized, documented, coordinated, or evaluated. The LBL Self-Assessment Program has been developed to address all of these issues.

The LBL Self-Assessment Program provides an internal review system that promotes a high level of performance in the Laboratory's ES\&H programs. The Program involves a continuous process of information gathering at all levels, with the purpose of determining whether procedures designed to obtain a high level of performance (for example, quality assurance and conduct of operations procedures) are being followed adequately, and, if they aren't, of determining the appropriate corrective actions.

Guidance for development of the LBL Self-Assessment Program is provided by DOE Order $5482.1 \mathrm{~B},{ }^{1} \mathrm{DOE}$ Order $5700.6 \mathrm{C}^{2}$ the Secretary of Energy, ${ }^{3}$ the Office of Energy Research, ${ }^{4}$ the San Francisco Field Office, ${ }^{5}$ and a DOE Interoffice Task Force. ${ }^{6}$ In accordance with this guidance, the LBL SelfAssessment Program formalizes and supplements existing self-assessment procedures to ensure accountability, allow trend analysis, promote timely and effective implementation of corrective actions, and improve communication of ES\&H information.

\section{GOALS AND OBJECTIVES}

The goals of the LBL Self-Assessment Program are to:

- Ensure implementation of the Laboratory's policy to "provide a safe and healthful working environment for its employees, participating guests and visitors... to prevent any harm to these individuals, the general public, or to the environment as a result of Laboratory activities... [and] to protect Laboratory property from damage or loss from accidents or other causes."7

- Ensure compliance with ES\&H requirements while fulfilling the scientific research mission.

The objectives of the LBL Self-Assessment Program are to:

- Provide a mechanism that enables divisions and support organizations to identify performance objectives and to compare their actual operations with Laboratory performance objectives. 
- Provide a mechanism that enables management and support organizations to continuously improve performance.

- Ensure timely identification and correction of ES\&H deficiencies.

- Prevent the occurrence of future potential ES\&H deficiencies.

- Integrate ES\&H activities into line management operations.

- Establish continuous communication between LBL. Divisions and support organizations charged with ES\&H responsibilities.

- Establish continuous lines of communication between management and staff on ES\&H matters.

\section{SCOPE}

The LBL Self-Assessment Program is intended to evaluate the performance of Laboratory operations, programs, facilities, projects, and management infrastructure. The LBL Self-Assessment Program also applies to off-site DOE-controlled facilities. ${ }^{8}$ Although the initial focus and catalyst for implementing a formal self-assessment program at LBL is to achieve ES\&H objectives (see Appendix A for ES\&H areas of inquiry), the program described in this document may also be used to evaluate other, non-ES\&H objectives, as they are identified by Laboratory management or DOE requirements.

\section{IMPLEMENTATION AUTHORITY AND RESPONSIBILITIES FOR SELF-ASSESSMENT}

The Laboratory Director is responsible for:

- Exercising the authority to carry out Laboratory policy and interpreting requirements for environmental protection, safety, and health placed upon the University of California.

- Ensuring full cooperation by Divisions/Offices in implementing the Self-Assessment Program.

The Associate Laboratory Director for Operations is responsible for:

- Establishing minimum self-assessment programmatic requirements for all Divisions and Offices.

- Providing the necessary training and support resources to ensure efficient implementation of the LBL institutional Self-Assessment Program.

Division Directors and Office Heads ${ }^{9}$ are responsible for:

- Developing, documenting, and implementing the Division's/Office's self-assessment program, including identifying a responsible person(s) for self-assessment.

- Ensuring that the Division/Office programs conforms with overall LBL and DOE requirements.

- Allocating Division/Office staff and budget to implement self-assessment program activities.

In addition, the Director of the Environment, Health and Safety Division is responsible for:

- Evaluating the compliance status of Divisions/Offices regarding ES\&H policies and procedures.

- Ensuring effective communication of ES\&H information. 
The Head of the Office of Assessment and Assurance (OAA) is responsible for coordinating development, documentation, and implementation of the institutional and Division/Office self-assessment programs.

\section{OVERVIEW OF THE LBL SELF-ASSESSMENT PROGRAM}

The LBL self-assessment process generates targeted performance data through evaluations conducted at all levels of the Laboratory organization. The data are analyzed against established standards to identify strengths, areas for improvement, and corrective actions. An effective communication system has been established to convey findings to appropriate line organizations and staff members throughout the Laboratory, and an effective tracking system ensures timely implementation of corrective actions.

The institutional self-assessment program consists of the division-level programs and additional oversight functions provided by the EH\&S Division and the Office of Assessment and Assurance (OAA). The focus of the institutional-level program is to efficiently integrate and coordinate division activities so that they conform with DOE and Laboratory requirements. The Division/Office program's focus is to develop procedures that are specific to the division's operations and available resources. Successful implementation of the division-level programs is key to the Laboratory Self-Assessment Program.

The LBL Self-Assessment Program is a three-ticr process in which each Division/Office is evaluated by:

- The Division/Office Appraisal Team (self-appraisal)

- An Environment, Health and Safety Division Functional Team (independent appraisal)

- An OAA Management Appraisal Team (independent appraisal)

Self-appraisals are conducted by units within the line organization to assess their own performance. Independent appraisals are conducted by technical staff from the Environment, Health and Safety Division and OAA, who are not directly responsible for the activities being evaluated.

The primary source of documentation for self-assessment activities is the Notebooks System, which LBL has developed to satisfy quality assurance, conduct of operations, and other DOE Orders requirements. The Notebooks contain critical information on facilities, research programs, and administrative/support activities. Notebook owners use the Notebooks to articulate their organizations' internal requirements, appraisal findings, and corrective actions.

\section{LBL SELF-ASSESSMENT PROGRAM ELEMENTS}

All division-level self-assessment programs must contain the following basic elements (see Figure 1).

- Performance objectives and criteria,

- Appraisals,

- Performance analysis,

- Follow-up on corrective actions,

- Training of appraisal and analysis teams, and

- Communication of ES\&H information

These elements are described below. Each division program must include a five-year appraisal schedule. 


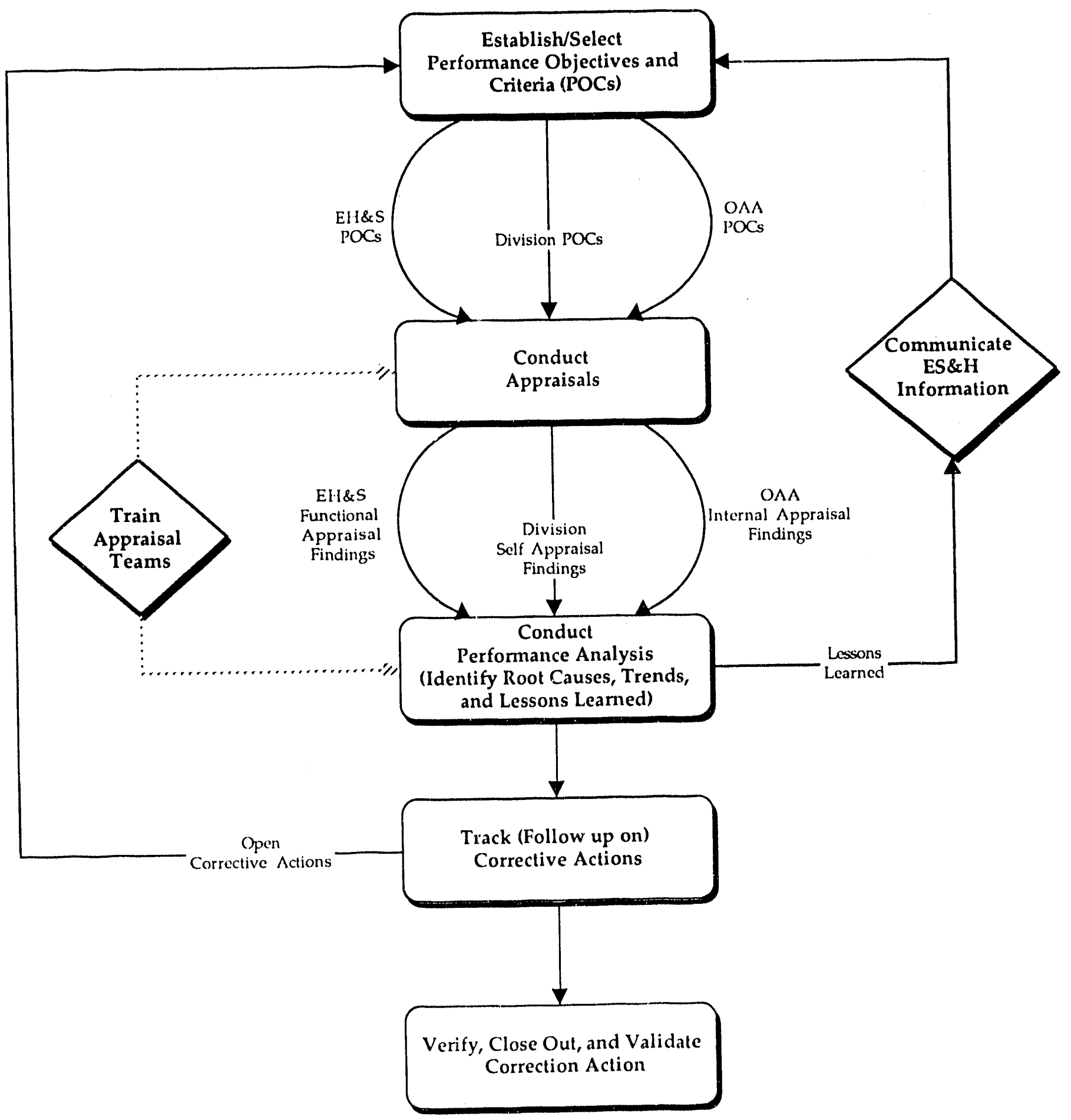

Figure 1. LBL Self-Assessment Program 


\section{Performance Objectives and Criteria}

On the basis of Laboratory policy and past appraisals by the Laboratory or DOE, the OAA initially identifies performance objiectives and criteria and obtains Director's Action Committee concurrence. Individual Divisions and Offices may then supplement the OAA-defined performance objectives. These objectives and criteria set the standards against which Divisions and Offices evaluate their operations, facilities, and programs, and are updated annually by OAA. See Table 1 for examples.

Table 1. Example of Performance Objectives and Criteria for Emergency Preparedness

\begin{tabular}{|c|c|c|}
\hline Type of Appraisal & Performance Objective & Performance Criteria \\
\hline $\begin{array}{l}\text { Division Self- } \\
\text { Appraisal }\end{array}$ & $\begin{array}{l}\text { Building occupants are } \\
\text { adequately prepared for } \\
\text { emergencies. }\end{array}$ & $\begin{array}{l}\text { - There is an up-to-date and facility-specific } \\
\text { Building Emergency Plan. } \\
\text { - Building occupants know the name } \\
\text { of the Emergency Team Leader. } \\
\text { - Building occupants know the } \\
\text { locations of the assembly areas and } \\
\text { evacuation routes. } \\
\text { - Selected building occupants are } \\
\text { trained in shutdown procedures for } \\
\text { utility valves, switches, and any } \\
\text { other special shutdown } \\
\text { requirements in the building. }\end{array}$ \\
\hline $\begin{array}{l}\text { EH\&S Division } \\
\text { Functional Appraisals }\end{array}$ & $\begin{array}{l}\text { A building or building } \\
\text { complex emergency } \\
\text { preparedness program has } \\
\text { been established and is } \\
\text { adequate to prepare occupants } \\
\text { for proper and immediate } \\
\text { response to emergency } \\
\text { situations. }\end{array}$ & $\begin{array}{l}\text { - Building Emergency Response Plans } \\
\text { are up to date, complete, and } \\
\text { specific to the building or complex. } \\
\text { - Building occupants are familiar with } \\
\text { the Building Emergency Response } \\
\text { Plan. } \\
\text { - Supervisors/managers are familiar } \\
\text { with the Building Emergency } \\
\text { Response Plan. } \\
\text { - The Building Emergency Team is } \\
\text { trained on proper response. }\end{array}$ \\
\hline $\begin{array}{l}\text { OAA } \\
\text { Management } \\
\text { Appraisals }\end{array}$ & $\begin{array}{l}\text { Emergency preparedness } \\
\text { organization and } \\
\text { administration in the } \\
\text { Laboratory ensures effective } \\
\text { control of site emergencies } \\
\text { (Laboratory-wide). }\end{array}$ & $\begin{array}{l}100 \text { percent of audited Emergency } \\
\text { Response Plans are considered } \\
\text { adequate by the EH\&S Division. } \\
\text { - Performance standards established } \\
\text { in DOE Order } 5500.10 \text { - Emergency } \\
\text { Readiness Plans are met. }\end{array}$ \\
\hline
\end{tabular}




\section{Appraisals}

Self-assessment appraisals enable management to determine its level of success in meeting preestablished performance objectives and criteria. Appraisal observations are recorded in a structured manner (e.g., by a computer tracking system) to support proposed corrective actions and subsequent trend analysis (see Perforinance Analysis element below). Appraisal techniques and methods are listed in Table 2.

In the course of conducting an appraisal, corrective actions may be identified for relatively minor findings (deficiencies). For more serious or chronic deficiencies, further analysis of performance data may be necessary to identify the appropriate corrective action (see Performance Analysis element below). Appraisals also reveal noteworthy practices that promote ES\&H or other performance objectives.

Table 2. Appraisal Techniques

\begin{tabular}{|c|c|}
\hline $\begin{array}{l}\text { Interviews with Division management } \\
\text { - Interviews with Division Safety Committee } \\
\text { members } \\
\text { - Interviews with Division personnel } \\
\text { - Reviews of documentation, e.g., LBL } \\
\text { Notebooks } \\
\text { - Inspections and surveys of areas, e.g., } \\
\text { workplace safety checklists }\end{array}$ & $\begin{array}{l}\text { - Reviews of past assessments conducted } \\
\text { internally or by contracted appraisal services, } \\
\text { DOE, or external regulatory bodies } \\
\text { - Reviews of corrective action records } \\
\text { - Environmental monitoring } \\
\text { - Personnel exposure monitoring }\end{array}$ \\
\hline
\end{tabular}

Three distinct categories of appraisals are conducted as part of the LBL Self-Assessment Program:

Division Self-Appraisals. Each Division a id Office evaluates its own performance in following ES\&H, quality assurance, conduct of operé ions, and other DOE or Laboratory-mandated procedures. It then compares its findings with established performance objectives and criteria. Divisions/Offices appraise each of their departments (facilities) annually. For the first two years following implementation of the Institutional Program, Divisions/Offices must perform their selfappraisals at least annually. Thereafter, departrnental facilities may be evaluated at intervals of up to two years, if the hazards identified in previous appraisals justify the longer interval. An example of a performance objective and criteria for a division self-appraisal is shown in Table 1 .

Environment, Health and Safety Division Functional Appraisals. The Environment, Health and Safety Division conducts functional appraisals of other Divisions and Offices to evaluate their compliance with Laboratory ES\&H procedures. Facilities (and projects) must be inspected at least once every three years. Facilities may be scheduled more or less frequently if the scheduling is warranted by internal or external appraisals and is consistent with DOE Order 5482.1B. The frequency of functional appraisals (for a given facility) depends on an evaluation by the Environment, Health and Safety Division of the associated hazards or risks. Table 1 gives an example of a performance objective and criteria for a functional appraisal.

OAA Management Appraisals. The OAA audits selective line management activities of all Divisions (including the Environment, Health and Safety Divisiori) and Offices to evaluate their effectiveness in ensuring that ES\&H, quality assurance, conduct of operations, and other program goals are being met. Each Office and Division must receive a management appraisal at least once every three years. As part of the management appraisal process, the OAA coordinates the results of the triennial reviews conducted by the Laboratory's Safety Review Committce and incorporates them into its appraisal. The Associate Laboratory Director for Operations will arrange for an independent review of OAA's performance within the required triennial review period. Table 1 gives an example of a performance objective and of criteria for a management appraisal. 


\section{Performance Analysis}

OAA and each Division and Office conduct performance analyses of appraisal findings to identify root causes and associated corrective actions; to identify trends; and to identify lessons learned. The results of performance analyses are documented as follows:

Root Cause Analysis. A root cause is the most basic causal factor for a deficiency or finding. Action taken to correct a root cause is more likely to prevent recurrence of an event than is correction of a causal factor that is not a root cause. Personnel error and procedural failure are examples of root causes. Root cause analysis is routinely performed for lost time injuries, permit violations, environmental citations, accidents, and Laboratory-reportable occurrences. Significant root causes are reported through the Laboratory's Lessons Learned Program (see below).

Trend Analysis. Divisions/Offices perform trend analysis (over time and within the Laboratory) on appraisal findings, root causes, and performance indicators to identify whether there are significant or Laboratory-wide problems not readily apparent from an appraisal for a single time period or a single division. 10 The trend analysis element of the LBL Self-Assessment Program expands upon the LBL Performance Indicator and Trending Program, which collects data on personnel safety, operational incidents, environmental releases, and management. The Laboratory uses its computer tracking systems for corrective actions to provide trending capabilities (see Follow-up on Corrective Actions below).

Lessons Learned Program. A computer data base of lessons learned is used by the Central Training Office (CTO) to disseminate both positive and negative lessons from self-assessment findings. These lessons supplement those identified from investigations by the Environment, Health and Safety Division of Laboratory occurrences (as documented in LBL Occurrence Reports) and DOE-provided Lessons Learned.

\section{Follow-up on Corrective Actions}

Each Division and Office follows up on corrective actions by identifying persons/departments (or other Laboratory Divisions or Offices) responsible for implementing corrective actions, allocating the necessary staff and budget resources, and tracking the progress, completion, and effectiveness of the corrective actions. Divisions/Offices are responsible for tracking and closing out only those corrective actions for which they have funding responsibility. Close-out of corrective actions is tracked (and documented) by the following computer data bases:

LBL Corrective Action Tracking System (LCATS). LCATS is a Laboratory-wide system, maintained by OAA, for tracking high-priority or institutional corrective actions. For example, LCATS tracks corrective actions identified through independent external reviews (such as the 1991 Tiger Team corrective actions), serious violations, and corrective regulatory actions identified by Divisions, that require funding at the institutional level. LCATS also tracks milestones, verification data on close-outs, validation dates of close-outs, and financial resource requirements. Using the data from LCATS, OAA reports progress quarterly to the DOE San Francisco Ficld Office.

LBL Self-Assessment Data Base (LSAD). The Divisions/Offices maintain LSAD to track their corrective actions and to perform trend analyses. LSAD and other external audit findings (e.g., by the DOE, University of California, or City of Berkeley) are elevated to the LCATS based on evaluations performed by OAA. 


\section{Communication of ES\&H Information}

Documented appraisal findings, results from the performance analysis, and progress in completion of corrective actions are forrnally communicated horizontally and vertically in the line organizations through the following reports (based on a fiscal year):

Frorn each Laboratory Division/Office:

- Quarterly Division/Office LSAD reports on Division/Office corrective actioris (to the OAA)

- Annual Division/Office self-appraisal reports (to the OAf)

- Division-level Lessons Le,drner (to Environment, Health and Safety Division for their review)

- Occurrence Reports (to Environment, Health and Safety Division for their review)

From the Environmen:, Health \& Safety Division (additional):

- Annual Environment, Health and Safety Functional Appraisal Report (to the OAA)

- Quarterly Environmental Compliance Report

- Lessons Learned Reports (to the CTO for ciissemination)

- Quarterly Performance Indicator Reports (to DOE and Divisions/Offices)

From the Office of Assessment and Assurance:

- Annual LBL Self-Assessment Repo، . (to DOE)

- Quarterly LCATS reports on Laboratory corrective actions (to DOE)

- Lessons Learned (to Environment, Health and Safety Division for their review)

- Mid-Year Performance Analysis/Trend Report

Training of Appraisal and Performance Analysis Teams

Appraisals and performance analyses are performed by qualified and knowledgeable members of an appraisal team established by each Division and Office for its self-assessment program. The teams identify their training needs and seek training resources through OAA, the Environment, Health and Safety Division, and the Laboratory's (CTO). Appraisal team members receive training in auditing methods, ES\&H procedures, quality assurance, and conduct of operations. Team members conducting performance analysis and follow-up tracking receive training in root cause analysis, lessons learned, occurrence reporting, and corrective action data base management systems. All training for the divisionlevel self-assessment program is documented, and a roster of qualified individuals is maintained by the Division and Office.

\section{PROCEDURES FOR DIVISIONS AND OFFICES TO IMPLEMENT SELF-ASSESSMENT}

Divisions and Offices are responsible for developing and implementing their individual sels-assessment programs in accordance with the elements set forth in this program plan. An LBL Self-Assessment 
Manual prepared by the OAA provides comprehensive information and guidance to assist Divisions and Offices execute their self-assessment activities, including preparation and periodic updating of divisionlevel self-assessment program implementation plans. The manual incorporates the experiences and findings of a pilot implementation of i. self-assessment program and of lessons learned from actual program implementaiion.

To implement a self-assessment program, each Division and Office:

- Designates a person (and/or committee) responsible for program development and implementation.

- Prepares a division-level self-assessment program implementation plan.

- Develops a five-year appraisal schedule that includes report due dates (subject to OAA approval)

- Designates an appraisal (and analysis) team.

- Assigns self-assessment functions to the responsible person and team members.

- Identifies the training needs of the appraisal (and analysis) team members.

- Arranges for self-assessment training.

Division-level program implementation plans are reviewed and approved by the OAA. This ensures that Division/Office operations are evaluated against a set of the minimum acceptable performance objectives and criteria established Laboratory-wide, and that programs are consistent with the institutional program elements. A format for a division-level seif-assessment program implementation plan is provided in Appendix B.

\section{IMPLEMENTATION SCHEDULE}

OAA coordinates management appraisals of the Laboratory Divisions and Offices, following a five-year schedule as shown in Table 3. 
Table 3. Five-Year Schedule of OAA Management Appraisals

\begin{tabular}{|c|c|c|c|c|c|c|c|c|c|c|c|c|c|c|c|c|c|c|c|c|}
\hline \multirow{3}{*}{ Division/Office } & \multicolumn{4}{|c|}{ Year 1} & \multicolumn{4}{|c|}{ Year 2} & \multicolumn{4}{|c|}{ Year 3} & \multicolumn{4}{|c|}{ Year 4} & \multicolumn{4}{|c|}{ Year 5} \\
\hline & \multicolumn{4}{|c|}{ Quarter } & \multicolumn{4}{|c|}{ Quarter } & \multicolumn{4}{|c|}{ Quarter } & \multicolumn{4}{|c|}{ Quarter } & \multicolumn{4}{|c|}{ Quarter } \\
\hline & 1 & 2 & 3 & 4 & 1 & 2 & 3 & 4 & 1 & 2 & 3 & 4 & 1 & 2 & 3 & 4 & 1 & 2 & 3 & 4 \\
\hline Administration & & & & & & & • & & & & & & & & & & & & - & \\
\hline Structural Biology & & & & & & & & - & & & & & & & & & & & & • \\
\hline Accel Fusion Res & & & & & & - & & & & & & & & & & & & - & & \\
\hline Physics & & & & & - & & & & & & & & & & & & $\bullet$ & & & \\
\hline EH\&S & & • & & & & & & & & & & & & $\bullet$ & & & & & & \\
\hline Info Computing Sci & & & - & & & & & & & & & & & & $\bullet$ & & & & & \\
\hline Engineering & • & & & & & & & & & & & & - & & & & & & & \\
\hline Nuclear Science & & & & & & & & & & & & - & & & & & & & & \\
\hline Life Sciences & - & & & & & & & & & & - & & & & & & & & & \\
\hline Chemical Sciences & & & & - & & & & & & & & & & & & • & & & & \\
\hline Earth Sciences & & & & & & & & & & • & & & & & & & & & & \\
\hline Energy \& Env & & & & & & & & & • & & & & & & & & & & & \\
\hline Material Sciences & & & - & & & & & & & & & & & & - & & & & & \\
\hline All Offices & & & & & - & & & & & & & & & & & & - & & & \\
\hline
\end{tabular}


NOTES

1. Environment, Safety \& Health Appraisal Program, U.S. DOE, September 23, 1986.

2. Quality Assurance, U.S. DOE, August 21, 1991.

3. Guidance on Environment, Safety and Health Self-Assessment," U.S. DOE, July 31, 1990.

4. Energy Research Self Assessment Program, U.S. DOE, July 11, 1991.

5. Self Assessment Program Implementation Plan, U.S. DOE - San Francisco Field Office, 1992.

6. Draft Self-Assessment Guidance Document, U.S. DOE, January 16, 1992.

7. Lawrence Berkeley Laboratory Health and Safety Manual (PUB-3000) Lawrence Berkeley Laboratory.

8. LBL activities in non-DOE-controlled areas on the University of California (UC), Berkeley campus (also referred to as Appendix B Space) are not covered by this Self-Assessment Program. Selfassessment activities in this space are described in a Memorandum-of-Understanding between LBL and the UC Berkeley campus.

9. The term "Offices" refers to organizations that are not a part of a Laboratory Division. Currently, these include the Office of the Laboratory Director, Office of the Deputy Director, Office of the Associate Director at Large, Laboratory Counsel, Office for Planning and Development, Office of the Associate Laboratory Director for Operations, and the Office of Assessment and Assurance.

10. Trend analysis is currently performed by the Environment, Health and Safety Division as part of the Laboratory's Performance Indicator and Trending Program. 
APPENDIX A

Table A-1. LBL Self-Assessment Program Areas of Inquiry

\begin{tabular}{|c|c|c|}
\hline & & Area of Inquiry \\
\hline \multirow[t]{2}{*}{ Environment } & Media & Non-Media Specific \\
\hline & $\begin{array}{l}\text { Air } \\
\text { Soil } \\
\text { Sediment } \\
\text { Biota } \\
\text { Surface water } \\
\text { Groundwater }\end{array}$ & $\begin{array}{l}\text { Solid, hazardous, radioactive, mixed waste mgmt. } \\
\text { Toxic \& hazardous materials management } \\
\text { Radiation and radiological materials management } \\
\text { Quality assurance/conduct of operations } \\
\text { Environmental monitoring } \\
\text { Emergency preparedness/chemical inventories } \\
\text { NEPA \& CEQA implementation } \\
\text { Special topics (e.g., historic/cultural resources, } \\
\text { endangered species, floodplain/wetlands, etc.) }\end{array}$ \\
\hline Safety \& Health & $\begin{array}{l}\text { Organization/administration } \\
\text { Maintenance } \\
\text { Packaging and transportation } \\
\text { Medical services } \\
\text { Fire protection } \\
\text { Organization \& admin resources } \\
\text { Management systems } \\
\text { ES\&H policy/procedures } \\
\text { Planning and budgeting } \\
\text { Self-assessment/corrective action } \\
\text { Communication }\end{array}$ & $\begin{array}{l}\text { Operations } \\
\text { Training and certification } \\
\text { Emergency preparedness } \\
\text { Site/facility safety review } \\
\text { Quality verification } \\
\text { Radiological protection } \\
\text { Occupational safety } \\
\text { Worker safety and health compliance (OSHA) } \\
\text { Industrial hygiene } \\
\text { Mgmt. qualification, involvement, \& commitment } \\
\text { Occurrence reporting and trend analysis }\end{array}$ \\
\hline $\begin{array}{l}\text { Management \& } \\
\text { Organization }\end{array}$ & $\begin{array}{l}\text { Organization \& administration } \\
\text { Resources } \\
\text { Management systems } \\
\text { ES\&H policy/procedures } \\
\text { Planning and budgeting }\end{array}$ & $\begin{array}{l}\text { Mgmt. qualification, involvement \& commitı vent } \\
\text { Communication } \\
\text { Occurrence reporting and trend analysis } \\
\text { Self-assessment/corrective action }\end{array}$ \\
\hline
\end{tabular}




\section{APPENDIX B \\ OUTLINE FOR DIVISION-LEVEL SELF-ASSESSMENT PROGRAM IMPLEMENTATION PLAN}

I. Introduction

Provide a brief description of the Division's/Office's self-assessment program (The Office of Assessment and Assurance (OAA) will provide a generic description that Divisions/Offices may modify, as desired).

II. Policy

Provide the Division Director's/Head of Office statement of policy (The OAA will provide a generic description that Divisions/Offices may modify, as desired).

III. Purpose

Describe the purpose of the Division's/Office's self-assessment program (The OAA will provide a generic description that Divisions/Offices may modify, as desired).

IV. Responsibilities

Identify the person responsible for developing and implementing the Division's/Office's program. Identify members of the appraisal and performance analysis team(s).

V. Program Elements

A. Performance Objectives and Criteria - List performance objectives and criteria provided by the OAA; list additional (if any) performance objectives and criteria established by the Division/Office.

B. Self-appraisal - Describe self-appraisal method(s) for each performance objective and programmatic unit. Identify schedule of self-appraisals such that each programmatic unit is evaluated at least once per year (more frequently if warranted by an EH\&S Division hazard analysis).

Describe methods for documenting self-appraisals, corrective actions, lessons learned, noteworthy practices, and root causes.

C. Performance Analysis - Describe how the Division/Office will use root cause analysis and trend analysis to identify corrective actions for chronic or serious deficiencies identified through self-appraisal. (The OAA will provide a generic description that Divisions/Offices may modify, as desired.)

D. Follow-up on Corrective Actions - Describe the Division's/Office's computer data base (LSAD) which is used to track self-appraisal findings and corrective actions. Include the 
criteria developed by OAA and the EH\&S Division for elevating LSAD corrective actions to LCATS. Divisions and Offices will provide input data to their respective LSADs.

Describe criteria and procedures for verification, close-out, and validation of a corrective action tracked by LSAD (OAA will identify suggested procedures).

E. Communication of ES\&H Information - Describe the methods (e.g. occurrence reports, staff meetings, quarterly corrective action reports) for communicating ES\&H information within the Division/Office, to the Environment, Health and Safety Division, and to the OAA.

F. Training - Describe the training needs of the appraisal and performance analysis team(s). OAA and the CTO will provide training criteria to the Divisions/Offices.

Describe the method for maintaining a roster of trained team members.

VI. Five-Year Appraisal Schedule

Provide a five-year schedule for self-appraisals (Divisions/Offices may conduct self-appraisals throughout the year). The schedule may be updated annually. 



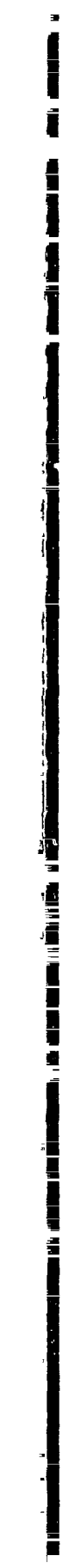

